\title{
Acquired Bartter-like Syndrome Presenting with Polyuria and Reversible Hypokalemia Associated with Colistin Use in a Critically Ill Pediatric Patient
}

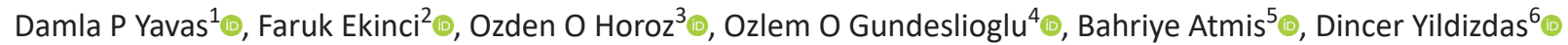

\begin{abstract}
We report a case of an acquired Bartter-like syndrome (BLS) after 3 days of treatment initiation and improved after discontinuation of colistin therapy in pediatric intensive care unit. A 2-month-old girl with spinal muscular atrophy type 1 who had respiratory distress received colistin therapy with a dose of $5 \mathrm{mg} / \mathrm{kg} / \mathrm{day}$ for Acinetobacter baumannii complex isolation from endotracheal aspirate on the 12th day follow-up. Polyuria ( $6 \mathrm{~mL} / \mathrm{kg} / \mathrm{hour}$ ) in the presence of normal blood pressure and hypokalemic metabolic alkalosis were developed on the $3 \mathrm{rd}$ day of colistin treatment. Colistin was stopped on the 4th day, and 2 days after discontinuation of colistin, polyuria improved dramatically. Her metabolic alkalosis and hypokalemia discontinued after 2 and 4 days, respectively.

There are very few reports about colistin-induced BLS. The onset of polyuria, hypokalemia, and metabolic alkalosis during treatment with colistin and resolution after interruption suggest a causative relationship.

Keywords: Bartter-like syndrome, Colistin, Hypokalemia, Pediatric, Polyuria.

Indian Journal of Critical Care Medicine (2021): 10.5005/jp-journals-10071-23898
\end{abstract}

\section{INTRODUCTION}

Colistin is a polypeptide antibiotic that belongs to the polymyxin class of cationic polypeptide antibiotics. ${ }^{1}$ The emergence of multidrug-resistant, gram-negative bacterial infections has resulted in a significant increase in the use of intravenous colistimethate sodium. ${ }^{2}$ Colistin has dose-dependent bactericidal effect and also postantibiotic effect against Acinetobacter baumannii, Pseudomonas aeruginosa, and Klebsiella pneumonia. ${ }^{3,4}$ Although colistin-associated nephrotoxicity has been previously reported on a wide range in the literature, there are very few reports about colistin-induced Bartter-like syndrome (BLS). BLS develops during treatment with different classes of drugs and is presented with hypokalemic metabolic alkalosis, hypomagnesemia, hypocalcemia, and normal serum creatinine levels. ${ }^{5}$ Herein we report a 2-monthold infant of an acquired BLS after 3 days of treatment initiation and improved after discontinuation of colistin therapy in pediatric intensive care unit (ICU).

\section{Case Description}

A 2-month-old girl with spinal muscular atrophy type 1, receiving high-flow nasal cannula (HFNC) due to respiratory distress, was transferred from another hospital to our pediatric ICU. On admission, she was slightly tachycardiac with a heart rate of 136/ minute, blood pressure was $111 / 63 \mathrm{~mm} \mathrm{Hg}, \mathrm{SpO}_{2}$ was $100 \%$, and capillary refilling was 2 seconds. On physical examination, she had tachypnea and her intercostal retractions and auscultation of the lungs revealed bilateral secretory rales. Preliminary blood gas and complete blood count were as follows: $\mathrm{pH}: 7.38, \mathrm{pCO}_{2}: 55 \mathrm{~mm} \mathrm{Hg}$, $\mathrm{pO}_{2}: 83 \mathrm{~mm} \mathrm{Hg}, \mathrm{HCO}_{3}: 26$, lactate: $1.3 \mathrm{mmol} / \mathrm{L}, \mathrm{Hb}: 9.4 \mathrm{~g} / \mathrm{dL}, \mathrm{WBC}$ : $8.9 \times 10^{3} \mu \mathrm{L}$, platelets: $403 \times 10^{3} \mu \mathrm{L}, \mathrm{BUN}$ : $1.2 \mathrm{mg} / \mathrm{dL}$, creatinine: $0.06 \mathrm{mg} / \mathrm{dL}$, albumin: $34 \mathrm{~g} / \mathrm{L}$, sodium: $136 \mathrm{mEq} / \mathrm{L}$, potassium: $4 \mathrm{mg} / \mathrm{dL}$, phosphate: $4.2 \mathrm{mg} / \mathrm{dL}$, calcium: $9.8 \mathrm{mg} / \mathrm{dL}$, magnesium: $2 \mathrm{mg} / \mathrm{dL}$, and procalcitonin: $0.2 \mathrm{ng} / \mathrm{mL}$ (0-0.5 normal range).

\begin{abstract}
1-3,6 Department of Pediatric Intensive Care, Cukurova University, Faculty of Medicine, Adana, Turkey

${ }^{4}$ Department of Pediatric Infectious Disease, Cukurova University, Faculty of Medicine, Adana, Turkey

${ }^{5}$ Department of Pediatric Nephrology, Cukurova University, Faculty of Medicine, Adana, Turkey

Corresponding Author: Damla P Yavas, Department of Pediatric Intensive Care, Cukurova University, Faculty of Medicine, Adana, Turkey, Phone: +90 32245868 68, e-mail: damlapinaryavas@gmail.com

How to cite this article: Yavas DP, Ekinci F, Horoz OO, Gundeslioglu OO, Atmis B, Yildizdas D. Acquired Bartter-like Syndrome Presenting with Polyuria and Reversible Hypokalemia Associated with Colistin Use in a Critically III Pediatric Patient. Indian J Crit Care Med 2021;25(7):822-824.
\end{abstract}

Source of support: Nil

Conflict of interest: None

We continued HFNC oxygen therapy and cefotaxime treatment for her pneumonia that she was already receiving. On the 2 nd day of intensive care hospitalization, she required noninvasive ventilation through bilevel positive airway pressure due to the recurrent apneic episodes. The patient developed progressively increasing respiratory distress, and her chest X-ray showed new-onset infiltrates in the lower lobe of the left lung. Lung ultrasound showed increased localized B-lines in the zone 1 of the right lung. Meropenem and amikacin were initiated to extend the antimicrobial spectrum, and cefotaxime was discontinued.

On the 10th day follow-up, due to the persistence of recurrent apnea and worsening of respiratory failure while in noninvasive ventilation, patient underwent tracheostomy. Two days after tracheostomy procedure, patient's ventilatory pressures needed to be increased and she developed worsening respiratory distress 
despite invasive mechanical ventilation. A. baumannii complex $\left(10^{5}\right.$ colony) was isolated from endotracheal aspirate that is sensitive only to colistin. Intravenous colistin was initiated with a dose of $5 \mathrm{mg} / \mathrm{kg} /$ day and divided into two equal doses. The patient received amikacin with colistin, and meropenem therapy was discontinued.

Polyuria (6 mL/kg/hour) in the presence of normal blood pressure and hypokalemic metabolic alkalosis developed on the 3rd day of colistin treatment. The patient did not have any diarrhea or vomiting. Serum sodium, magnesium, calcium, chloride, and serum creatinine concentrations were within the normal range. Her blood test revealed serum potassium $2.5 \mathrm{mg} / \mathrm{dL}$, albumin $25 \mathrm{~g} / \mathrm{L}$, and serum bicarbonate $29 \mathrm{mEq} / \mathrm{L}$ that increased to $35 \mathrm{mEq} / \mathrm{L}$ on the 4 th day of colistin therapy. Polyuria with urine output was around $6-8 \mathrm{~mL} / \mathrm{kg} / \mathrm{hour}$. Urine studies showed urine spot potassium was $25 \mathrm{mEq} / \mathrm{L}$ and urine potassium creatinine ratio was $2: 3 \mathrm{mEq} / \mathrm{mg}$. Urine density was 1003 . Renal ultrasonography was normal. Colistin was stopped on the 4th day; meropenem and tigecycline were initiated. Daily potassium supplementation was given. Daily intravenous fluid supplementation was increased by $30 \%$.

Two days after discontinuation of colistin, polyuria improved dramatically. Her metabolic alkalosis and hypokalemia discontinued after 2 and 4 days, respectively. On the 23 rd day of hospitalization, her pneumonia showed regression, tracheal aspirate cultures showed any bacterial growth, and she was discharged to the general ward. The daily urine output, serum potassium, bicarbonate and $\mathrm{pH}$ levels were shown in Figure 1.

\section{Discussion}

Pharmacological studies on nephrotoxicity mechanisms of colistin have been neglected because it was off the market for a long time. ${ }^{6}$ Renal damage due to colistin is considered a result of its detergent activity for many years, but it induces membrane permeability, increases intracellular cations, anions, and water, and results in cell lysis, which have been proposed to be due to colistin's nephrotoxicity mechanism. In animal studies, antioxidant therapies have shown promising results in protecting the kidney. ${ }^{7}$ Colistin nephrotoxicity is defined as an increase in serum creatinine to a level of $>2 \mathrm{mg} / \mathrm{dL}$, a $50 \%$ reduction in GFR, or a decline in renal function leading to a need for renal replacement therapy. ${ }^{8}$ It is usually reversible.

Bartter syndrome (BS) is an autosomal recessive disease characterized by hypokalemia, hypochloremia, metabolic alkalosis, and hypercalciuria. Renin and aldosterone levels are increased, but blood pressure is normal. Primary pathology in BS is in the thick ascending limb of the loop of Henle. ${ }^{9}$ As a result of the influence of $\mathrm{Na} / \mathrm{K} / 2 \mathrm{Cl}$, apical $\mathrm{K}$, and basal chloride channels in the membrane, renal wasting of $\mathrm{Na}, \mathrm{K}$, and $\mathrm{Cl}$ occurs. Volume depletion also develops. BLS develops during treatment with different classes of drugs, including tuberculostatics and aminoglycosides, and is characterized by hypokalemic metabolic alkalosis, hypomagnesemia, hypocalcemia, and normal serum creatinine levels. It is unclear how prolonged use of colistin can cause such tubulopathy.

In recent case reports, BLS due to colistin therapy has been reported in only one child case who is a preterm infant. Following the literature, a total of five cases who developed BLS after colistin therapy have been reported; however, only two cases reported having polyuria after a short time (3-4 days) of colistin therapy. The association of colistin with hypokalemia was reported previously. ${ }^{10}$ We know about aminoglycoside-induced BLS. Colistin may directly activate the calcium-sensing receptor in the thick ascending loop of Henle and the distal tubule similar to aminoglycosides and result in hypokalemia, metabolic alkalosis, hypocalcemia, hypomagnesemia, and hypercalciuria. ${ }^{7-11}$

In our case, BLS developed on the 3rd day of colistin treatment, and she had already received amikacin for 12 days; symptoms disappeared only after colistin was discontinued. Also, amikacin treatment was continued after colistin, making it a causative factor, and not taking any diuretics suggests that colistin is the causative drug. In recent case reports, the onset of BLS after starting

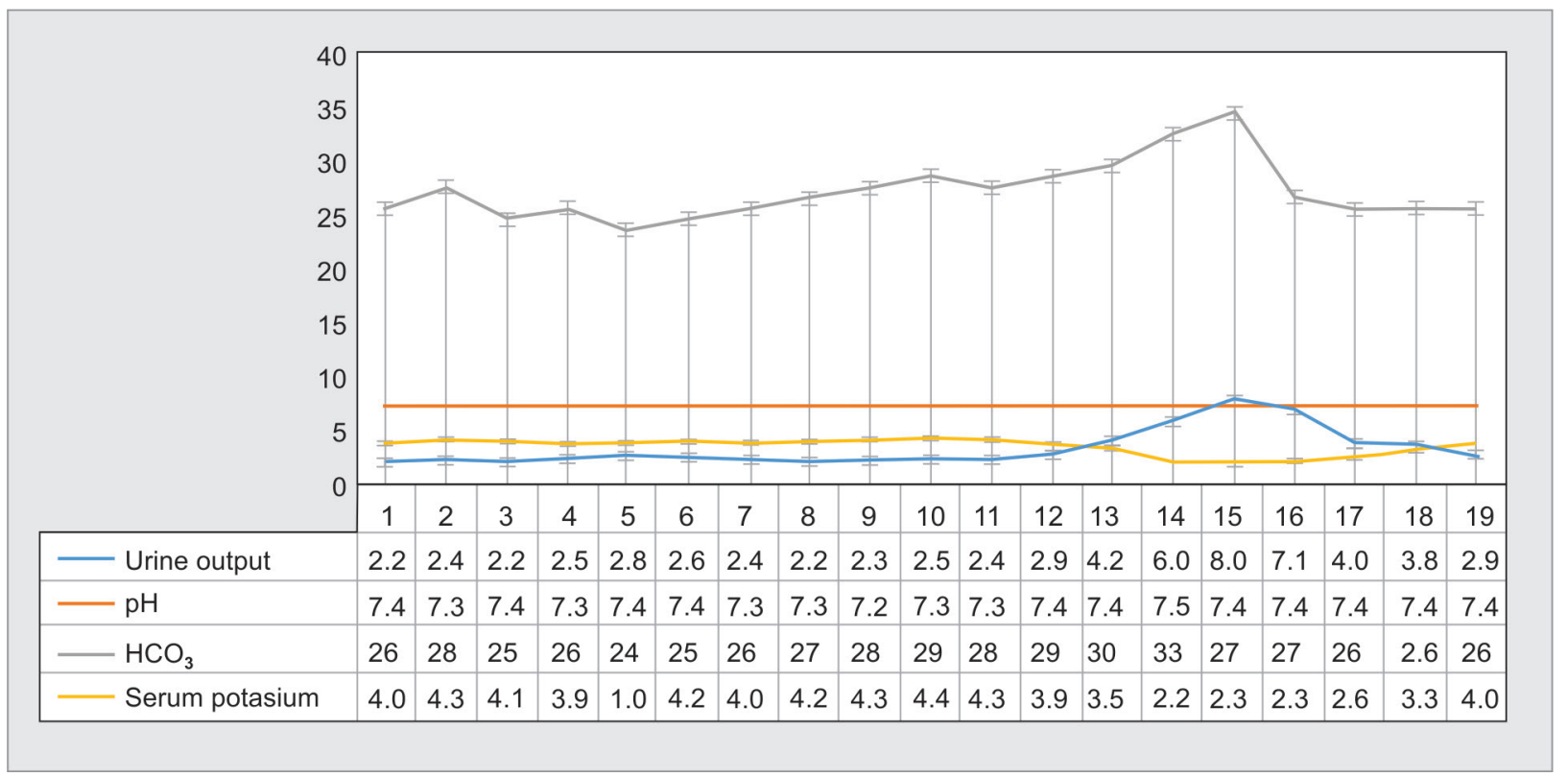

Fig. 1: Graphical representation of serum potassium, serum bicarbonate, and 24-hour urinary output trend. Day 12: Colistin started; Day 15: Colistin stopped 
colistin therapy was, respectively, 3 days, 4 days, 9 days, 2 weeks, and 4 weeks. Only hypokalemia was developed with polyuria in the patient, and other electrolytes and serum creatinine levels were normal. We did not continue colistin because of significant hypokalemia and polyuria, and the patient also showed a remarkable improvement in lung function and other markers of sepsis after changing the treatment.

\section{Conclusion}

Our case received colistin $5 \mathrm{mg} / \mathrm{kg} / \mathrm{day}$ in two doses, and there is not any literature about the dosage and frequency of colistin administration for tubulopathies beside serum creatinine levels. The onset of the metabolic alterations during treatment with colistin and resolution after interruption suggest a causative relationship. More pharmacological studies are needed about colistin's nephrotoxicity and tubulopathy in critically ill children.

\section{HighLights}

Colistin should be considered as the causative agent for BLS. BLS due to colistin therapy has been reported in a total of five cases, and only one of them was a child, that is, a preterm infant.

\section{Authors' Contributions}

D.P.Y., F.E., O.O.H., O.O.G., B.A., and D.Y. treated the patient and were responsible for the concept, design, and acquisition of data. D.P.Y. wrote the first draft of the manuscript; F.E., O.O.H., and D.Y. revised and edited the manuscript. O.O.G. and B.A. collected the data and were responsible for the literature search. All authors read and approved the final version of the manuscript.

\section{Consent}

Written informed consent was obtained from the patient for publication of this case report and any accompanying images.

\section{Ethical Standard}

We confirm that we have read the Journal's position on issues involved in ethical publication and affirm that this report is consistent with those guidelines. All authors approved the final article.

\section{ORCID}

Damla P Yavas (ㄴ) https://orcid.org/0000-0002-0424-4155

Faruk Ekinci $\odot$ https://orcid.org/0000-0001-6675-3150

Ozden O Horoz ๑ https://orcid.org/0000-0001-7590-650X

Ozlem O Gundeslioglu ำ https://orcid.org/0000-0003-2202-7645

Bahriye Atmis @ https://orcid.org/0000-0002-1133-4845

Dincer Yildizdas @ https://orcid.org/0000-0003-0739-5108

\section{References}

1. Li J, Nation RI, Turnidge JD, Milne RW, Coulthard K, Rayner CR, et al. Colistin: the re-emerging antibiotic for multidrug-resistant Gram negative bacterial infections. Lancet Infect Dis 2006;6(9):589-601. DOI: 10.1016/S1473-3099(06)70580-1.

2. Tabish M, Mahendran M, Ray A, Vikram NK. Colistin-induced acquiredBartter-like syndrome: an unusual cause of meltdown. BMJ Case Rep 2020;13:e232630. DOI: 10.1136/bcr-2019-232630.

3. Poirel L, Jayol A, Nordmann P. Polymyxins: antibacterial activity, susceptibility testing, and resistance mechanisms encoded by plasmids or chromosomes. Clin Microbiol Rev 2017;30(2):557-596. DOI: 10.1128/CMR.00064-16.

4. Javan AO, Shokouhi S, Sahraei Z. A review on colistin nephrotoxicity. Eur J Clin Pharmacol 2015;71(7):801-810. DOI: 10.1007/s00228-015-1865-4.

5. Cakir U, Alan S, ZeybekC, Erdeve O, Atasay B, Yalcinkaya F, et al. Acquired bartter-like syndrome associated with colistin use in a preterm infant. Ren Fail 2013;35(3):411-413. DOI: 10.3109/0886022X.2012.761084.

6. Gai Z, Samodelov SL, Kullak-Ublick GA, Visentin M. Molecular mechanisms of colistin-induced nephrotoxicity. Molecules 2019;24(3):653. DOI: 10.3390/molecules24030653.

7. Berg JR, Spilker CM, Lewis SA. Modulation of polymyxin B effects on mammalian urinary bladder. Am J Physiol 1998;275(2):F204-F215. DOI: 10.1152/ajprenal.1998.275.2.

8. Florescu DF, Qiu F, McCartan MA, Mindru C, Fey PD, Kalil A. What is the efficacy and safety of colistin for the treatment of ventilatorassociated pneumonia? A systematic review and meta regression. Clin Infect Dis 54(5):670-680. DOI: 10.1093/cid/cir934.

9. Lee BH, Cho HY, Lee H, Han KH, Kang HG, Ha IS, et al. Genetic basis of Bartter syndrome in Korea. Nephrol Dial Transplant 2012;27(4):15161521. DOI: $10.1093 / \mathrm{ndt} / \mathrm{gfr} 475$.

10. Ben Salem C, Hmouda H, Bouraoui K. Drug-induced hypokalaemia. Curr Drug Saf 2009;4(1):55-61. DOI: 10.2174/157488609787354369.

11. Kwon J-A, Lee JE, Huh W, Peck KR, Kim Y-G, Kim DJ, et al. Predictors of acute kidney injury associated with intravenous colistin treatment. Int J Antimicrob Agents 2010;35(5):473-477. DOI: 10.1016/j. ijantimicag.2009.12.002. 